\title{
EL DEBATE SOBRE DECOLONIALIDAD, ASPECTOS INDÍGENAS Y MEDIO AMBIENTE EN AMÉRICA LATINA. UN ANÁLISIS SOBRE EL ESTADO DEL ARTE
}

\author{
THE DEBATE ON DECOLONIALITY, INDIGENOUS \\ ASPECTS AND ENVIRONMENT IN LATIN AMERICA. AN \\ ANALYSIS OF THE CURRENT SITUATION
}

\begin{abstract}
LE DÉBAT SUR LA DÉCOLONIALITÉ, LES PEUPLES AUTOCHTONES ET L'ENVIRONNEMENT EN AMÉRIQUE LATINE. UNE ANALYSE SUR L'ÉTAT DE LA TECHNIQUE
\end{abstract}

\author{
Elías David Morales Martínez \\ Universidad Federal del $A B C$ \\ davidmorales.ri@gmail.com \\ JÉSSICa Girão FlorênCio \\ Universidad Federal del $A B C$ \\ girao.jessica@gmail.com
}

Resumen: La perspectiva decolonial como aportación teórica de agendas de investigaciones latinoamericanas viene creciendo significativamente en la región. Entendiendo la demanda por la creación de esta perspectiva por causa de las peculiaridades del proceso de colonialismo en América Latina, muchas temáticas consideran este aporte como fundamental para analizar trabajos científicos. En ese sentido, este artículo pretende hacer una revisión del estado del arte de la utilización de la perspectiva modernidad/colonialidad/ decolonialidad con respecto de las cuestiones indígenas y ambientales. El objetivo es verificar las tendencias de la agenda decolonial según las temáticas indígenas y ambientales y, por tanto, medir las potencialidades de nuevos ejes y dimensiones de investigación en estas áreas.

Palabras clave: estado del arte, decolonialidad, cuestiones indígenas, medio ambiente, América Latina.

Abstract: The decolonial perspective as a theoretical contribution by Latin American research agendas is growing significantly in the region. Understanding the demand for the creation of this perspective as a result of the specific features of the colonial process in Latin America, many themes view this con- 
tribution as fundamental for the analysis of scientific research. Consequently, this paper seeks to undertake a review of the current situation with regard to the use of the modernity/coloniality/decoloniality perspective with regard to indigenous and environmental issues. The aim is to verify the trends in the decolonial agenda according to indigenous and environmental themes, and therefore assess the potential of new approaches and dimensions of research in these areas.

Keywords: current situation, decoloniality, indigenous issues, environment, Latin America.

\section{Traducción de Gonzalo Celorio Morayta}

Résumé: L'approche "décoloniale" est un apport théorique de l'Amérique latine. Son développement s'explique par le processus colonial même dans cette région, dont elle reflète la singularité; son influence croissante tient au fait qu'elle est profitable à l'analyse scientifique. L'article examine l'utilisation de la perspective de modernité-colonialité-décolonialité pour l'étude des peuples autochtones et de l'environnement. Cela permet de confirmer les tendances de l'agenda décolonial dans ces deux domaines et d'estimer le potentiel des nouvelles recherches à leur égard.

Mots clefs: État de la technique, décolonialité, peuples autochtones, environnement, Amérique latine.

Traducción de Bernardo Mabire

Fecha de recepción: septiembre de 2016 Fecha de aceptación: mayo de 2017 
$\mathrm{L}$ OS DEBATES y las discusiones acerca de las herencias del colonialismo en los países de América Latina se han multiplicado en los últimos años y muestran una novedad en relación con la historia de las ciencias sociales, una vez que la consolidación de este campo de análisis particular aconteció solamente a finales de la década de 1990. En este contexto, se estructuraron en América Latina los estudios de la modernidad/colonialidad/decolonialidad, cuyos principales teóricos han sido Edgardo Lander, Arturo Escobar, Walter Mignolo, Enrique Dussel, Aníbal Quijano, Fernando Coronil, Ramon Grosfóguel, Santiago Castro-Gómez, Catherine Walsh y Nelson Maldonado-Torres. El surgimiento de esta perspectiva fue una demanda de las especificidades latinoamericanas de su proceso de colonización.

Por el hecho de que en los últimos años la agenda de investigación bajo la perspectiva de la decolonialidad en América Latina ha ido aumentando, este artículo pretende hacer un estado del arte de la utilización de esta aportación en relación con dos aspectos de enorme recurrencia en sus análisis: las cuestiones indígenas y ambientales. Por tanto, este trabajo se divide en cuatro partes: la primera pretende elucidar las circunstancias históricas de la consolidación del grupo precursor de la decolonialidad ${ }^{1}$ latinoamericana, el grupo modernidad/colonialidad, y presentar los principales puntos de la discusión decolonial. La segunda expone la metodología de búsqueda utilizada para encontrar las investigaciones relevantes en el área. En la tercera, se mostrarán los artículos, disertaciones y tesis encontradas a partir de la metodología de búsqueda y se presentarán sus principales contribuciones al campo de estudio. Por último, se harán las consideracio-

${ }^{1}$ Según W. Mignolo, decolonial significa "pensar a partir de la exterioridad y en una posición epistémica subalterna de frente a la hegemonía epistémica que crea, construye y establece un entorno exterior con el fin de asegurar su interioridad" ("Desobediência epistêmica: a opção descolonial e o significado de identidade em política", Cadernos de Letras da UFF, núm. 34, 2008, p. 304). La traducción de esta cita, como la de nota 17, pertenece a los autores. 
nes finales con la intención de trazar las tendencias y potencialidades que esta nueva perspectiva decolonial condensa en el proceso de recientes sistematizaciones de ejes temáticos para el análisis de la realidad latinoamericana.

\section{LA CONSOLIDACIÓN DE LA PERSPECTIVA}

DE DECOLONIALIDAD EN AMÉrica LATINA

Los países latinoamericanos tuvieron su construcción política, económica y social -a partir de la estructuración del Estado-nación- de forma muy similar a causa del proceso común que tuvieron entre ellos: la colonización. Fue en esta particularidad que muchos pensadores de la región vieron la demanda por una teorización específica de la realidad latinoamericana para entender las herencias que nuestras sociabilidades sufrieron y que todavía continúan marcadas.

Las principales influencias de este giro epistemológico desde América Latina fueron los teóricos del poscolonialismo, que surgió de los estudios culturales y literarios de Europa y de Estados Unidos. El principal marco de las perspectivas que se fundamentaron en la relación colonial antagónica entre colonizados y colonizadores, aun antes de una legitimación del poscolonialismo, fueron los escritos de Franz Fanon, ${ }^{2}$ quien discutió la imposibilidad de la construcción de una identidad en la presencia del otro colonizador. ${ }^{3}$ De la misma manera, Aimé Césaire, Albert Memmi ${ }^{4}$ y Edward Said $^{5}$ fueron importantes referentes para las teorizaciones latinoamericanas.

${ }^{2}$ Su obra más influyente es Los condenados de la tierra (2007).

${ }^{3}$ L. Ballestrin, "América Latina e o giro decolonial”, Revista Brasileira de Ciência Política, núm. 11, 2013, pp. 89-117.

${ }^{4}$ Conocidos como el trío francés del pensamiento poscolonial, Fanon, Césaire y Memmi (los dos primeros originarios de Martinica, el último de Túnez) se consideran los portavoces de los colonizados.

${ }^{5}$ Orientalismo (2007) es su trabajo más importante en relación con los estudios poscoloniales. 
Durante la década de 1970, en Asia, se fundó el Grupo de Estudios Subalternos, liderado por Ranajit Guha, cuyo propósito era analizar críticamente la historiografía de India, contextualizándola a partir de la influencia europea. Este grupo, que tuvo como principal referencia al autor Antonio Gramsci, fue crítico de intelectuales occidentales posestructuralistas y desconstruccionistas, como por ejemplo Deleuze y Foucault, una vez que, según ha observado la teórica de los estudios subalternos Gayatri Spivak, ${ }^{6}$ el intelectual poscolonial no puede hablar en nombre de los subalternos, porque ese acto de resistencia estaría superpuesto al propio discurso hegemónico. ${ }^{7}$ Ya en la década de 1980, la principal influencia de los estudios poscoloniales en las ciencias sociales fueron los culturalistas Homi Bhabha, Stuart Hall y Paul Gilroy. ${ }^{8}$

El punto de partida de las concepciones latinoamericanas poscoloniales fue al inicio de los años noventa, cuando el Grupo Latinoamericano de Estudios Subalternos, que se inspiró en la experiencia del Subaltern Studies Group de India, comenzó a ser organizado por varios pensadores de diferentes países latinoamericanos. Este grupo se presentó oficialmente en 1994 durante la Conferencia de la Asociación de Estudios Latinoamericanos -LASA, cuando promulgaron sus ideales con el Manifiesto Inaugural..$^{9}$ Sin embargo, uno de los miembros del grupo, Walter Mignolo, defendió por entonces que los estudios poscoloniales y subalternos no se habían desvinculado lo suficiente de teorizaciones eurocéntricas y no se podría utilizar los referenciales de India, porque se debería consolidar las bases peculiares del colonialismo lati-

${ }^{6}$ Su obra ¿Puede el subalterno hablar? (2010) se tiene por su mayor contribución a los estudios poscoloniales.

${ }^{7} \mathrm{~L}$. Ballestrin, art. cit.

${ }^{8}$ Sus obras más importantes son El lugar de la cultura (1994), Da Diáspora (2003) y Atlántico negro (1995), respectivamente.

9 S. Castro-Gómez, "Geografías poscoloniales y translocalizaciones narrativas de «lo latinoamericano». La crítica al colonialismo en tiempos de globalización", en R. Follari y R. Lanz (comps.), Enfoques sobre posmodernidad en América Latina, Caracas, Sentido, 1998, pp. 157-182. 
noamericano como etapa esencial para el desarrollo del capitalismo mundial. ${ }^{10}$

Por las divergencias internas, el grupo fue disuelto y paralelamente se fundó en 1998 el grupo modernidad/colonialidad $(\mathrm{M} / \mathrm{C})$. Entre los principales teóricos que participaron de las discusiones, unos más que otros, se hallan de algún modo Edgardo Lander, Arturo Escobar, Walter Mignolo, Enrique Dussel, Aníbal Quijano, Fernando Coronil, Ramón Grosfoguel, Augustín Lao-Montes, Immanuel Wallerstein, Santiago Castro-Gómez, Oscar Guardiola, Zulma Palermo, Freya Schiwy, Javier Sanjinés, Catherine Walsh, Nelson Maldonado-Torres, José David Saldívar, Lewis Gordon, Boaventura de Sousa Santos, Margarita Cervantes de Salazar, Libia Grueso, Marcelo Fernández Osco, Jorge Sanjinés, Ana Margarita CervantesRodríguez, Linda Alcoff, Eduardo Mendieta, Eliana Vuola, Marisa Belausteguigoitia y Cristina Rojas. ${ }^{11}$

En relación con los debates que se sostuvieron en este grupo, uno de los principales fue entender la colonialidad como resultado del periodo colonial y como lógica que aún pauta las sociabilidades e instituciones latinoamericanas. La colonialidad se basa en la dominación y la jerarquización de las sociedades y de esta forma se configuran las relaciones de poder en América Latina. Este modelo de poder, derivado de la modernidad, solamente tuvo éxito cuando la región fue dominada por pueblos europeos, puesto que tiene como pilares el eurocentrismo, el capitalismo y el Estado-nación. ${ }^{12}$ Este encuentro entre los pueblos originarios y europeos se desarrolló por medio de la sumisión de las culturas indígenas con el propósito de explotar los recursos y naturaleza latinoamericanos. La dinámica de ese proceso de dominación fue la idea de raza -que surgió del contacto entre pueblos originarios y europeos- y la idea de capital-sueldo y de

${ }^{10}$ L. Ballestrin, art. cit.

11 Idem.

12 A. Quijano, "Colonialidade, poder, globalização e democracia”, Novos Rumos, núm. 37, 2002, pp. 4-28. 
mercado mundial para la explotación del trabajo y el control de las formas de producción, cuya lógica de poder se tiene por legítima en todo el mundo:

La expresión "colonialidad del poder" designa un proceso fundamental de estructuración del sistema-mundo moderno/ colonial, que articula los lugares periféricos de la división internacional del trabajo con la jerarquía étnico-racial global y con la inscripción de migrantes del Tercer Mundo en la jerarquía étnico-racial de las ciudades metropolitanas globales. Los Estados-nación periféricos y los pueblos no-europeos viven hoy bajo el régimen de la "colonialidad global" impuesto por los Estados Unidos, a través del Fondo Monetario Internacional, del Banco Mundial, del Pentágono y de la OTAN. Las zonas periféricas se mantienen en una situación colonial, aunque ya no estén sujetas a una administración colonial. ${ }^{13}$

Otro concepto que ha sufrido con la colonialidad ha sido el saber, el conocimiento, del cual se deriva el racismo epistémico (concepto de Maldonado-Torres) y la negación de la alteridad epistémica (expresión de Castro-Gómez). ${ }^{14}$ Mignolo afirma que algunas poblaciones, como las indígenas, tuvieron sus intereses negados con la agencia epistémica dominante. La solución para este problema de subyugación sería la desobediencia epistémica, que promueve el proceso de decolonialidad por medio de la emergencia de pensamientos de frontera. El concepto de "giro decolonial" fue teorizado por Maldonado-Torres, en 2005, y fue contextualizado como el tercer elemento de la modernidad/colonialidad, ${ }^{15}$ el cual significa la acción y la lucha contra los pilares que sostienen la colonialidad. A esto hay que sumar el hecho de que atender a

${ }^{13}$ R. Grosfoguel, "Para descolonizar os estudos de economia politica e os estudos pos-coloniais: transmodernidade, pensamento de fronteira e colonialidade global", Revista Crítica de Ciências Sociais, núm. 80, 2008, p. 126 (apud L. Ballestrin, art. cit., p. 100).

${ }^{14} \mathrm{~L}$. Ballestrin, art cit.

${ }^{15} \mathrm{Id}$. 
las poblaciones indígenas tiene como propósito que sus derechos sean respetados a partir del mantenimiento del medio ambiente en que éstas se encuentran y se desarrollan con el aumento de su dinámica comunitaria al igual que las lógicas dominantes.

En los análisis decoloniales, la racionalidad europea (RE) conceptualiza la naturaleza como subyugada al sistema moderno capitalista. Ese proceso ha afectado directamente las dinámicas culturales indígenas una vez que la naturaleza es su medio de sobrevivencia. De manera general, el ser humano se asienta, cuando se conecta material y simbólicamente a su territorio. ${ }^{16}$ En ese sentido, es posible entender que la colonialidad desestabilizó las territorialidades indígenas al introducir nuevas formas de interacción con la naturaleza. ${ }^{17}$ Por tanto, las manifestaciones políticas, económicas, sociales y culturales indígenas que tuvieron lugar sobre esa base territorial (territorialización) fueron afectadas por los modelos de acumulación de capital históricamente vigentes. En este sentido, entender cómo el patrón de poder de la colonialidad dicta el entendimiento sobre la naturaleza es una delimitación necesaria para estudiar las cuestiones indígenas bajo el aporte decolonial.

Sobre estas caracterizaciones de las epistemologías latinoamericanas con respecto de la decolonialidad, y entendiendo el proceso histórico de su consolidación, es que se desarrolla nuestro análisis sobre el estado del arte de esta temática en América Latina. Igualmente pretendemos averiguar cómo se

${ }^{16}$ R. Haesbaert y C. W. Porto-Gonçalves, A nova desordem mundial, São Paulo, UNESP, 2006.

${ }^{17}$ Según Raffestin, "de esas relaciones de poder entre los «actores»y el espacio surge una «territorialidad», es decir, un sentimiento o noción territorial que es fruto de sus «relaciones existenciales» o "productivas», del modo como los individuos y colectividades se relacionan con sus respectivos cuadros y sistemas territoriales, en los cuales las relaciones de poder, en todas las escalas, son evidentemente preponderantes" (apud W. M. da Costa, "Tendências e perspectivas atuais", en Geografia Política e Geopolítica, São Paulo, Universidade de São Paulo, 2010, p. 320). 
articula la tendencia que toman las recientes investigaciones que utilizan la decolonialidad como perspectiva teórica para analizar las temáticas que tratan las cuestiones indígenas y ambientales en la región.

\section{METOdOLOGÍA IMPLEMENTADA PARA LA OBTENCIÓN DE DATOS}

Este artículo pretende analizar el estado del arte sobre las temáticas de las cuestiones indígenas y ambientales bajo las interpretaciones teóricas de la decolonialidad. Un artículo de esta naturaleza tiene objetivos bibliográficos para trazar la producción académica relevante, intentando evidenciar lo que se ha afirmado y de la misma forma lo que se ha incorporado del mainstream de las discusiones que se han ido sosteniendo en este ámbito.

Este artículo, por tanto, es descriptivo con respecto de las investigaciones de las temáticas que se pretenden tratar. Entendemos que asumir una postura descriptiva ayudará a delinear cómo la decolonialidad ha ido utilizándse para tratar las cuestiones y problemáticas ambientales e indígenas. Este método es por naturaleza una herramienta muy utilizada en la elaboración de textos focalizados en análisis de estado del arte para estructurar un debate sobre esa perspectiva teórica.

De esta manera, la pregunta que guía esta investigación es: ¿de qué forma las vertientes de decolonialidad, respecto de los análisis sobre las cuestiones indígenas y ambientales se han ido construyendo en América Latina? A partir de eso, se pretende estructurar las tendencias de las agendas de investigación y las potencialidades de interdisciplinariedad que presentan. Así, como bien se observa a partir de la delimitación expuesta, América Latina constituye el espacio de observación de las investigaciones llevadas a cabo en este análisis. Por consiguiente, consideramos necesario estudiar diferentes producciones bibliográficas como disertaciones 
de maestría, tesis de doctorado y artículos relevantes y de influencia académica.

Como herramienta de búsqueda para esos trabajos, se utilizaron las siguientes plataformas en línea de reconocidos acervos:

1) Portal de Periódicos Capes (http://www.periodicos.capes.gov.br/);

2) JSTOR (http://www.jstor.org/);

3) Sistema P@arthenon (http://www.parthenon.biblioteca.unesp.br:1701/primo_library/libweb/action/ search.do?vid=Unesp);

4) Sistema de Bibliotecas da Unicamp (SBU) (http://www. sbu.unicamp.br/);

5) Google Académico (https://scholar.google.com.br/);

6) Biblioteca Digital Brasileira de Teses e Dissertações (http:/ / bdtd.ibict.br/vufind/);

7) Springer (http://www.springer.com/br/).

Como criterios de búsqueda en estas plataformas, se usaron las palabras "decolonialidad", "indígena" y "ambiente", cuyos usos fueron repetidos de la misma manera en todas las plataformas (es decir fueron digitalizadas en los campos de búsqueda de esta manera: decolonialidad indígena ambiente). Para cubrir el mayor número de resultados posibles, estos términos también se buscaron en portugués (decolonialidade indígena ambiente) y en inglés (decoloniality indigenous environment).

Para la selección de los trabajos atinentes al propósito de nuestra investigación, se tomaron en cuenta textos originales que utilizan necesariamente el aporte teórico de la decolonialidad y sus teóricos ya mencionados. Se establecieron como criterios de inclusión en la selección de los textos, si el estudio o la investigación trata aspectos de América Latina y temáticas indígenas y ambientales. De esta forma, solamente se seleccionaron trabajos que son resultado de la estrategia de búsqueda con las palabras clave "decolonialidad indígena ambiente" y que traten obligatoriamente de estas temáticas como delimitación de investigación simultáneos. Como criterios de exclusión, se tuvo en cuenta si el estudio o la investiga- 
ción no tiene como ámbito de discusión, de forma simultánea y como objeto principal de análisis, la decolonialidad y las cuestiones indígenas y ambientales en el contexto de América Latina, así como textos que no correspondieron a ninguno de los idiomas utilizados (español, portugués o inglés).

La metodología elegida se basa en las plataformas digitales, porque pretende privilegiar las investigaciones recientes en esa temática, toda vez que estas discusiones vienen ganando mayor terreno en el debate del mundo académico. Por último, el límite temporal de trabajos seleccionados es el primer semestre de 2016.

Así, se elaboró este estado del arte, en cuyas consideraciones finales se pretende delinear los elementos más discutidos en la temática decolonial sobre cuestiones indígenas y ambientales, no menos que apuntar las potencialidades interdisciplinares y las demandas que en esta temática todavía tienen que discutirse y profundizarse.

\section{EL ESTADO DEL ARTE: INVESTIGACIONES RELEVANTES EN LA TEMÁTICA DE LA DECOLONIALIDAD SOBRE GUESTIONES INDÍGENAS Y AMBIENTALES}

A partir de las búsquedas realizadas para este artículo, al tener en cuenta la metodología explicada anteriormente, entre las investigaciones de la temática, el aspecto que más se destaca es el de Buen Vivir. ${ }^{18}$ Aunque el eje principal de la discusión del artículo sea otro, este concepto aparece con gran incidencia en las investigaciones y estudios encontrados.

${ }^{18}$ El Buen Vivir, o Bien Vivir, se considera una alternativa para concebir nuevas lógicas de desarrollo. Esta práctica se origina en las culturas indígenas, las cuales ya habían ampliado sus conceptos filosóficos para promover nuevas sociabilidades y propiciar la articulación entre seres humanos y naturaleza, la cual conduciría a una mejor calidad de vida en que la acumulación material no es ya una más de las premisas y la pluralidad cultural y étnica de las sociedades es evidencia de la democratización de las políticas públicas. 
Lizeth del Carmen Gómez Sierra y Miguel Ángel León, en su artículo de 2016, "De los derechos ambientales a los derechos de la naturaleza: racionalidades emancipadoras del derecho ambiental y nuevas narrativas constitucionales en Colombia, Ecuador y Bolivia”, siguen la ruta de lo que llaman crisis ambiental del siglo xxi y establecen dos preguntas: “¿cuál es la racionalidad que ha animado al Derecho Ambiental colombiano, para que, en todo caso, nos encontremos actualmente dentro de una crisis ambiental?"; ${ }^{19}$ y “¿dónde era posible localizar una racionalidad emancipadora de Derecho Ambiental?". ${ }^{20}$ Así, los autores parten de la premisa de que el Derecho Ambiental está fundamentado en la racionalidad moderna, concebida en el contexto de la colonialidad y, por eso, separa al ser humano de la naturaleza a partir de las influencias de las concepciones liberales. Como metodología, esta investigación establece la comparación entre las constituciones de Colombia, Bolivia y Ecuador, y observa que la emergencia de aspectos biocéntricos y sociocéntricos de estos marcos jurídicos son el resultado de un proceso de decolonialidad encabezado por los actores subyugados históricamente: indígenas, campesinos y negros. Este ejercicio de decolonialidad se materializa como el Buen Vivir, reconocido por las constituciones de Ecuador y Bolivia.

Esta investigación apunta a que las transformaciones constitucionales de esos países sea un intento para ampliar los Derechos Humanos y el debate ambiental en este ámbito. Además, el avance de los Derechos Ambientales junto con los Derechos de la Naturaleza -mediante mecanismos institucionales- también fue una conquista de Bolivia y Ecuador. La investigación concluye que Colombia necesita avanzar en los aportes jurídicos, como sus vecinos, para que se realice de la misma forma un giro decolonial en el país.

${ }^{19}$ L. del C. Gómez Sierra y M. Á. León, "De los derechos ambientales a los derechos de la naturaleza: racionalidades emancipadoras del derecho ambiental y nuevas narrativas constitucionales en Colombia, Ecuador y Bolivia”, Misión Jurídica, Bogotá, núm. 10, 2016, p. 234.

${ }^{20}$ Ibidem, p. 235. 
Aún en el eje del Buen Vivir, y al ser los principales teóricos de la temática, Eduardo Gudynas y Alberto Acosta, en su estudio titulado "La renovación de la crítica al desarrollo y el buen vivir como alternativa", ${ }^{21}$ tienen como objetivo revisar los aspectos claves del Buen Vivir, y utilizando los ejemplos de las constituciones de Bolivia y Ecuador lo entienden como una alternativa de desarrollo. Los autores discurren sobre los orígenes del concepto occidental de desarrollo (como lo contrario al subdesarrollo y producto de la colonialidad), pasando por las concepciones originadas en la CEPAL y observando la reafirmación del término con las olas neoliberales de las décadas de 1980 y 1990.

De ahí surgieron las críticas al posdesarrollo y el marco histórico importante para el ascenso de los gobiernos progresistas en Sudamérica. Esta situación propició el surgimiento de los movimientos indígenas y las epistemologías andinas, lo cual culminó en la conformación del concepto del Buen Vivir -que está siempre elaborándose y sufre la influencia tanto de la academia cuanto de los movimientos sociales. Así, esta investigación plantea las diferencias entre el Buen Vivir reconocido por Ecuador (sumak kawsay) y por Bolivia (ama qhilla, ama llulla, ama suwa, suma qamaña, ñandereko, teko kavi, ivi maraei, qhapaj ñan), de las cuales la primera atañe al derecho, mientras que la segunda, al orden ético-moral. El aspecto plural y pluricultural del Buen Vivir ha sido el que genera potencialidad para convertirse en elemento de la decolonialidad que cuestiona la modernidad y sus premisas desarrollistas.

Para discutir las bases del Buen Vivir a la luz del binomio etnicidad-desarrollo, Víctor Bretón Solo de Zaldívar escribió el artículo "Etnicidad, desarrollo y Buen Vivir: reflexiones críticas en perspectiva histórica". ${ }^{22} \mathrm{El}$ autor centra su estudio en los Andes equinocciales por entender precisamente que

${ }^{21}$ Revista Internacional de Filosofía Iberoamericana, núm. 53, 2011, pp. 71-83.

22 Revista Europea de Estudios Latinoamericanos y del Caribe, núm. 95, 2013, pp. 71-95. 
muchas de las investigaciones al respecto no hacen el debido ejercicio etnográfico. La hipótesis de Bretón es que el discurso del Buen Vivir se está introduciendo en un dispositivo de poder y se está distanciando de sus orígenes conceptuales, porque las sociedades han naturalizado una imagen estática de las culturas andinoamazónicas, con la cual los gobiernos considerados progresistas enmascaran sus verdaderos proyectos económicos. Así, el autor discute el ascenso en América Latina de los movimientos indígenas, principalmente en los años de 1990 y sus motivaciones, toda vez que fueron los sectores que más sufrieron con las políticas neoliberales de la época. Al mismo tiempo, se observó la necesidad del recorte de alteridad cultural en los espacios públicos de decisión -proceso que se denominó como multiculturalismo neoliberal. Fue en estas circunstancias que se estableció la Constitución de 2008 de Ecuador y su Revolución Ciudadana y en que el movimiento indígena que participó de la Asamblea que instauró la constitución no tenía la misma fuerza de aquel movimiento de los años noventa. El estudio de Bretón, por tanto, cuestiona que las formulaciones del Buen Vivir, que están en pleno ejercicio en Ecuador y Bolivia, sean movimientos que ponen las demandas indígenas en postulados neodesarrollistas. Además, señala la ruptura que el gobierno de Rafael Correa en Ecuador tuvo con el movimiento indígena.

A la inversa de esta perspectiva más crítica de la emergencia del Buen Vivir como herramienta decolonial utilizada por gobiernos sudamericanos para continuar con sus planes desarrollistas, la tesis de Marina Ghirotto Santos, A plurinacionalidade em disputa: sumak kawsay, autonomia indígena e Estado plurinacional no Equador (São Paulo, PUC-SP, 2015), tiene una visión más optimista del país. En su investigación, analizó los conceptos constitucionales de plurinacionalidad y de sumak kawsay, que define como posdesarrollistas y posextractivitas, alternativas a la colonialidad. La autora considera la ruptura del gobierno de Rafael Correa con los movimientos indígenas, como Víctor Zaldívar, y observa que este movimiento 
puede ocurrir por la diferente interpretación del texto constitucional. Como metodología, la investigadora documenta las tensiones entre el Estado y las comunidades indígenas de la región ecuatoriana de Pastaza.

Esta investigación observa el progreso a causa de la autonomía que las poblaciones indígenas ganan con el advenimiento del sumak kawsay, como resultado decolonial de una constitución plurinacional. Sin embargo, la autora considera el distanciamiento de las motivaciones indígenas y estatales con respecto del Buen Vivir, por el cual los gobiernos actuales ejercen un capitalismo de Estado basado en políticas extractivas. En su análisis, se constata que la relación entre el Estado ecuatoriano y los pueblos indígenas se da históricamente de forma colonial mediante los recortes racial, cultural y de clase. Por tanto, la opción decolonial del Buen Vivir encierra la alternativa de aumento de autonomía indígena para que estas poblaciones consigan colocar en el orden del día sus demandas.

Otros dos trabajos realizados en programas de posgrado encontrados en la búsqueda fueron la tesis de maestría Hydrocarbon conflict in the Peruvian Amazon: Indigenous people's decolonization of development and sustainability (Fort Collins, Colorado State University, 2010), de George Stetson, y la tesis de doctorado Usme: A space for hope. A case study of decolonial resistance and processes of deterritorialisation and reterritorialisation in Bogotá, Colombia (Melbourne, RMIT University, 2015), de Andrés Felipe Vargas Mariño. La primera investigación sostiene la hipótesis de que para las políticas de recursos naturales igualitarias es necesario repensar las que se adoptan en los territorios indígenas. Para comprobarla, el autor realiza un estudio de caso con respecto del conflicto causado por el desarrollo de hidrocarburos en territorios indígenas entre el gobierno de García y el Movimiento Indígena en la Amazonía Peruana (MIAP).

George Stetson concluye que es necesaria la decolonización de las políticas de recursos naturales, para que los indígenas ganen más control de decisión sobre estos recursos en 
sus territorios -toda vez que muchas de las reservas de hidrocarburos están en territorios indígenas y que las políticas de hidrocarburos son parte del régimen político de extracción de recursos naturales de Perú, con posibilidad de acción de la iniciativa privada.

El investigador argumenta que el posicionamiento del gobierno peruano se deriva de la idea colonial de que la Amazonía es un espacio vacío de utilización para el desarrollo nacional y que las poblaciones indígenas son obstáculos para este desarrollo. La alternativa posible a esta situación es la decolonización de las políticas públicas del país, donde el movimiento indígena -en este caso, el MIAP- es un actor que ejerce presión para el cambio.

En relación con la investigación de Andrés Mariño, el estudio de caso de la región de Usme, en Bogotá, es sobre la urbanización, como resultado de la cual se construyó el tercer basurero más grande de América Latina por medio de varios contratos de minerías multinacionales, incluidos los proyectos de vivienda que fueron mal planeados. De modo tal que la tesis de esta investigación consiste en argumentar que las transformaciones negativas son resultado del lado opresivo de la modernidad/colonialidad. Así, el gobierno local tiene la región por un depósito de recursos naturales para Bogotá, pero los movimientos campesinos -que en la visión del autor también abarca a los pueblos indígenas- cuestionan estas imposiciones, al hacer emerger sus concepciones de sociabilidades y de ambientalismo. Estas articulaciones pueden considerarse, según el autor, como luchas descolonizadoras por la justicia ambiental, al movilizarse contra las dinámicas generadas por estos procesos de urbanización. Como resultado, se tienen procesos de territorialización y reterritorialización encabezados por estas poblaciones, en que los actores movilizan sus identidades -por medio de las memorias colectivas de los grupos sociales campesinos- para entender sus espacios de vivencia y las formas que las estructuras materiales y sociales se articulan a partir de ese entendimiento. Estos movimientos campesinos se articulan, por 
tanto, para cuestionar su lugar periférico, resultado de la colonialidad, en la región de Bogotá y empoderarse a partir del proceso de reterritorialización.

Otra investigación sustentada en un estudio de caso acerca de los conflictos ambientales relacionados con poblaciones indígenas es la de Ximena Cuadra Montoya, "Conflictos ambientales en territorios indígenas y el rol de la reivindicación por el consentimiento libre, previo e informado: un análisis del caso Neltume en Chile". ${ }^{23}$ La autora comienza su artículo presentando la estimación del año 2002 del Instituto Nacional de Derechos Humanos de Chile, según la cual de los 97 conflictos ambientales que se registraron 37 ocurrieron en territorios indígenas. El propósito de la investigación es analizar cómo los conflictos ambientales derivados de proyectos extractivos, entendidos como acción política, influyen en esta realidad. Mediante el estudio de caso del Proyecto Central Hidroeléctrica Neltume (PCHN), se analiza cómo los indígenas son excluidos de los procesos decisorios.

Ximena Montoya parte de la premisa según la cual el ámbito social es inevitablemente espacio de conflictos y de antagonismos sociales que influyen en subordinaciones -los cuales, en este caso, la autora considera que derivan de las relaciones coloniales. El trabajo trata también de la limitación de los aparatos de consulta indígena que se erigieron en el país y las movilizaciones del pueblo Mapuche en la región del Neltume por el consentimiento libre, previo e informado. La alternativa que presenta la investigadora para este consentimiento consiste en la decolonización de la democracia liberal. La autora también observa la especificidad de los movimientos indígenas, dado que su diferencia cultural politiza sus reivindicaciones en conflictos ambientales, lo que los hace actores esenciales para el giro decolonial.

A propósito de la explotación minera, se cuenta con la investigación de Aída Sofía Rivera Sotelo y Luis Álvaro Pardo Becerra, que tiene por título “¿Qué minería aurífera, por quiénes

${ }^{23}$ Justiça do Direito, vol. 29, núm. 2, 2015, pp. 294-312. 
y con fines de qué desarrollo? Una mirada a la minería aurífera en la Zona Minera Indígena Remanso Chorrobocón”. ${ }^{24}$ A partir de un estudio de caso, este trabajo pretende cuestionar los discursos nacionales de desarrollo en Colombia que se basan en la ilegalidad jurídica. ${ }^{25}$ Así, los autores afirman que el ordenamiento jurídico del país es heredero del periodo monárquico colonial que concentra en el Estado el poder de administración de los suelos. La investigación cita el levantamiento del Censo Minero 2010-2011 del Ministerio de Minas y Energía, con el cual se puede demostrar que el mapa minero nacional se caracteriza por la ilegalidad y la informalidad y que, al mismo tiempo, el sector extractivo ha aumentado su producción en el país. La Amazonía en Colombia, en este contexto, es un espacio que sufre la explotación minera; incluso su territorio se designó zona estratégica de explotación.

De suerte tal que la zMI Remanso Chorrobocón fue la primera de esta naturaleza en Colombia. Esta zona ejemplifica los objetivos indígenas de explotación minera con minidragas. Sin embargo, sus actividades son ilegales, puesto que se realizan sin título y sin licencia ambiental. A pesar de esta situación, el estudio revela que las zonas de este tipo se inscriben en marcos jurídicos propios y que esta actividad es la alternativa para absorber la oferta de mano de obra de la región. Es en la cierta autonomía indígena de estas zonas que se configura la alternativa decolonial para los padrones de desarrollo modernos por medio de un pluralismo jurídico presente en estos espacios.

Con respecto de la degradación ambiental por medio de la construcción de infraestructuras, Ana María Chaparro realizó la investigación Visión de futuro indígena y su incidencia en el desarrollo en Colombia. El caso de las comunidades inga y kamëntza (Putamayo) ante la Iniciativa para la Integración de la

${ }^{24}$ Opera, núm. 14, 2014, pp. 95-117.

${ }^{25}$ Según palabras de Rivera Sotelo y Pardo Becerra, en su artículo cuestionan "el discurso de desarrollo extractivista facilitado por marcos jurídicos de ilegalidad, discurso que colisiona con visiones y prácticas de desarrollo local en la Zona Minera Indígena Remanso Chorrobocón” (p. 95). 
Infraestructura Regional Suramericana (Iirsa). ${ }^{26}$ Por este trabajo se entiende que la adopción de Colombia de la construcción de la variante San Francisco-Mocoa mediante Iirsa, en el marco del corredor vial Pasto-Mocoa, caracteriza la concepción que el gobierno tiene de desarrollo como crecimiento económico. Esta investigación busca desvelar de qué forma las comunidades indígenas articulan su comprensión de futuro con el concepto de desarrollo derivado de la comunidad internacional y la política nacional a partir del estudio de caso de las etnias Inga y Kamëntza ante la construcción de la autopista variante.

Las organizaciones, tanto indígenas como no indígenas, que se opusieron a este proyecto denunciaron que, además de no haberse consultado legítimamente a los pueblos tradicionales del área, tampoco hubo rigurosas evaluaciones socioambientales. Así, la autora observa que los movimientos indígenas son articulaciones de resistencia a dispositivos de poder y, al mismo tiempo, establecen espacios que también recrean otras relaciones de poder, en las que la diferencia se considera para que se constituya su identidad. De modo tal que estos movimientos continuamente se resisten a las estructuras de poder del sistema moderno/colonial.

Los Inga y Kamëntza, en particular, esperan que su territorio se legalice desde 1984. Esta situación, que se suma a las consecuencias ambientales de la construcción de la autopista variante, a los problemas de tensión urbana, al crecimiento de la población, a la falta de saneamiento básico, a la explotación de minerías y a la expansión de la frontera agrícola, empeoran las condiciones de vida de esas poblaciones. En ese sentido, estas comunidades se articulan no para rechazar los proyectos de desarrollo, sino para reclamar por la consulta previa, libre e informada para que puedan proponer la forma en que las comunidades podrían participar en los beneficios y perjuicios de la construcción de la variante.

${ }^{26}$ Bogotá, Universidad de los Andes, Centro Interdisciplinario de Estudios sobre Desarrollo (Cider), Ediciones Uniandes, 2015. 
La consecuencia es que estas etnias se suman por medio de la reafirmación de una condición común -la indígena- y hacen sus discursos flexibles para negociar sus intereses con las instituciones del Estado, poniendo su autonomía y autodeterminación en evidencia.

Asier Martínez de Bringas, con su artículo "La deconstrucción del concepto de propiedad: una aproximación intercultural a los derechos indígenas", ${ }^{27}$ trae a colación la discusión acerca del derecho moderno como marco jurídico para la propiedad territorial y ordenamiento del espacio. Esta dinámica determinó la dominación del espacio americano y de las poblaciones indígenas (a partir de parámetros raciales) por los colonizadores europeos. Este estudio trata el trinomio pueblos indígenas-hábitat-territorio y el desafío del diálogo intercultural para la emergencia de un Derecho Intercultural. Así, el autor tiene en cuenta el carácter multidimensional del territorio para los pueblos indígenas, en contraste con las premisas legitimadas de las culturas del Norte, que se basan en la idea de la propiedad liberal.

De esta manera, el estudio plantea los espacios internacionales de negociaciones ambientales en los que los pueblos indígenas pudieron participar de forma más consolidada: el Convenio Marco para prevenir el Cambio Climático (por medio del Foro Intergubernamental sobre Bosques) y el Convenio de Diversidad Biológica. Por tanto, para que sea posible un Derecho Intercultural es necesario que los Derechos Humanos introduzcan los parámetros indígenas de territorialidad comunitaria, con los que se trasciendan los marcos jurídicos de premisas liberales de propiedad y de la posibilidad de autonomía indígena -por el derecho de propiedad comunal indígena, de carácter consuetudinario- en sus territorios.

En el eje de localidades y glocalidades, Martha Angélica Soriano Sánchez desarrolló el trabajo "Glocalidades re-crea-

${ }^{27}$ Utopia y Praxis Latinoamericana, vol. 14, núm. 45, 2009, pp. 11-29. 
tivas. Ecología-política de la diferencia desde los caracoles zapatistas". ${ }^{28} \mathrm{Al}$ analizar la acción político-colectiva de las Juntas del Buen Gobierno (JBG), la autora se interesa por la ecología-política de la diferencia como alternativa de la crisis ambiental actual. Así, esta ecología habría surgido de la territorialidad y las localidades de los pueblos indígenas originarios como necesario contrapeso de las implicaciones de la globalización imperialista. De esta forma, la violencia en el sometimiento de poblaciones con sociabilidades diferentes a las occidentales y a sus principios genera las resistencias locales no occidentales.

El concepto "ecología política de la diferencia" se basa en Arturo Escobar, quien entiende la importancia de dotar de mayor fuerza a las redes glocales de autonomías contrahegemónicas. La investigadora Martha Soriano utiliza los movimientos zapatistas como ejemplo de comunidades que sufren con la colonialidad del poder y que pueden, por eso, influir con modelos de resignificación desde lo local-regional para poder idear alternativas ecológicas.

Aún más: en el eje de las lógicas del desarrollo, Jorge Montenegro realizó el estudio "Povos e comunidades tradicionais, desenvolvimento e decolonialidade: articulando un discurso fragmentado". ${ }^{29} \mathrm{El}$ autor inicia la discusión evidenciando la Política Nacional de Desarrollo Sostenible de los Pueblos y Comunidades Tradicionales (PNPCT) de Brasil, inspirada en la Convención 169 de la Organización Internacional del Trabajo (OIT) sobre Pueblos Indígenas y Tribales (1989). Esta normativa indica tres elementos para que los pueblos o las comunidades se autodefinan como tradicionales: “a) la comprensión dinámica de la tradición; b) la posibilidad de la autodefinición; y c) la imbricación entre territorio e identidad". ${ }^{30}$ Esta legislación es importante para la lucha y resistencia de estos grupos, porque no deja que sus identida-

28 Iberoamérica Social, núm. 2, 2014, pp. 104-115.

${ }^{29}$ Okara: Geografia em debate, vol. 6, núm. 1, 2012, pp. 163-174.

30 Ibid., p. 163. 
des sean esenciales, además de que reconoce el territorio como parte constituyente de esta identificación.

En este sentido, según Jorge Montenegro, se deben pensar las consecuencias del avance del capital en la cuestión agraria y en la lógica neoliberal. Especialmente, estos resultados afectan negativamente a las comunidades tradicionales del campo, que tienen sus dinámicas comunitarias de uso de los recursos por formas de resistencia al avance del capital privado y, al mismo tiempo, formas de exponer la importancia de marcos jurídicos de reforma agraria para que las supervivencias alternativas puedan continuar. En relación con los marcos jurídicos para promover cambios económicos y sociales, hay que decir que aún se construyen en la lógica de desarrollo occidental capitalista colonial y no consiguen comprender las dinámicas de las comunidades tradicionales.

Dos investigaciones encontradas con la metodología expuesta tienen ejes específicos: el ecosocialismo y el ecofeminismo. En el primer eje, Efendy Emiliano Maldonado hizo el estudio "Ecossocialismo indoamericano". ${ }^{31}$ A partir del análisis de los pueblos bolivianos y ecuatorianos, el autor evidencia la forma en que las demandas de los movimientos contrahegemónicos fueron introducidas en sus Constituciones con el propósito de fortalecer un ecosocialismo indoamericano, en cuanto que una Epistemología del Sur.

En este contexto, el autor critica a los gobiernos de izquierda latinoamericanos, no menos que a sus proyectos desarrollistas y tecnicistas, que pactaron alianzas con sectores de la burguesía para aumentar los lucros del capital en detrimento de la naturaleza. De esta forma, los pueblos indígenas, así como el proletariado, son los actores de cambio de esta lógica moderna/colonial. El paradigma productivo debe cambiar por una lógica comunitaria de los medios de producción para que las necesidades colectivas puedan garantizarse. Principalmente la necesidad de superar la concepción eurocéntrica de desarrollo con un giro decolonial y de interculturalidad. Así,

${ }^{31}$ Em Debate, núm. 9, 2013, pp. 56-73. 
el autor concluye considerando la importancia de la plurinacionalidad de las constituciones boliviana y ecuatoriana para alcanzar los objetivos de cambio ecosocialistas.

La investigación respecto al ecofeminismo, de Ana Gabriela Rincón Rubio, Ivonne Vizcarra Bordi y Humberto Thomé Ortiz, tiene por título "Prácticas espirituales, ecofeminismo y maíz nativo: el caso de las mujeres matlatzincas". ${ }^{32}$ El propósito del trabajo es

el acercamiento a las prácticas espirituales matlatzincas como mecanismo feminizado de resistencia simbólica para la conservación del maíz nativo, necesario para la subsistencia de las familias; cuyo sistema materializa diversas formas de asimetría y violencia entre géneros. Igualmente, es interesante observar el papel que ciertas prácticas tienen en la preservación de la cultura matlatzinca, como las relacionadas con la conservación de la lengua, las ceremonias y la vestimenta típica. ${ }^{33}$

De esta manera, el estudio pretendió comprender la espiritualidad sin utilizar cualquier aspecto que favorezca la opresión.

Las opciones decoloniales argumentan que la espiritualidad es una alternativa de emancipación en contextos neocoloniales, pero sin que se hiciera un recorte de género sobre el tema. Esta investigación pretendió hacerlo a partir del estudio de caso de la comunidad matlatzinca de San Francisco Oxtotilpan, en México. Se constató que la cosmovisión del matlatzinca tiene una importante relación con los alimentos, principalmente con el maíz nativo, y que las mujeres son las responsables por lo que hace al sector de la alimentación. Con respecto de la divinización femenina del maíz, la cual establece direcciones de tiempo, espacio y regeneración, es de hecho un elemento esencial para la organización social de

32 Mesa temática: Feminismos transnacionales, hermenéutica y políticas de identidad, pp. 1-15, en http://www.idaes.edu.ar/pdf_papeles/9-10\%2520 Ponencia_Rincon.pdf.

${ }^{33}$ Ibid., p. 2. 
la población. En relación con el aspecto masculino, éste también es esencial para la reproducción del maíz y de la dinámica comunitaria. La alteridad, en fin, es un elemento de gran importancia para esta comunidad.

Igualmente, en este estudio se pudo observar que las mujeres de esa comunidad ya habían criticado algunos puntos de la espiritualidad. Ellas ejercen cierta resistencia en el ámbito decolonial del cuidado que se debe tener de la naturaleza y, al mismo tiempo, entienden los roles estereotipados negativos de su vínculo con la naturaleza, problematizando que sus relaciones con ésta sean del mismo nivel que la del hombre con la naturaleza.

Con respecto del eje de educación ambiental, se encontraron dos investigaciones de la Universidade Federal do Ceará, en Brasil: por una parte, Saberes ancestrais indigenas dos Tapeba de Caucaia - CE: contribuições e diálogos com a educação ambiental dialógica, ${ }^{34}$ de Ana Karolina Pessoa Bastos Ximenes, y, por otra, Educação ambiental dialógica e descolonialidade com crianças indígenas Tremembé: vinculação afetiva pessoa-ambiente na Escola Maria Venância, ${ }^{35}$ de Deyseane Maria Araújo Lima.

La primera de las tesis tiene como objetivo principal exponer cómo los saberes ancestrales de los Tapeba de Caucaia, en Ceará, se relacionan con la Educación Ambiental Dialógica (EAD). Además, también se analiza cómo estos saberes son herramientas para la afirmación de la identidad indígena de los profesores de la etnia en la Escuela Diferenciada de Enseñanza Primaria y Secundaria de Trilho. En esta investigación se contextualiza la identidad indígena Tapeba y la forma en que se relaciona con los elementos capitalistas, modernos y neoliberales. También establece conexiones entre las características de la colonialidad/decolonialidad y la interculturalidad crítica con la pedagogía de los profesores de esta escuela.

${ }^{34}$ Tesis, Fortaleza, Universidade Federal do Ceará, 2012.

35 Tesis, Fortaleza, Universidade Federal do Ceará, 2014. 
El principal objetivo de esta investigación es mostrar la forma en que los profesores Tapeba relacionan los saberes indígenas con el modelo de educación eurocéntrico. Los saberes ancestrales indígenas son, según este trabajo, la alternativa decolonial para la Educación Ambiental Dialógica. La explicación de ello radicaría en el hecho de que los saberes ancestrales están ligados a la Madre Tierra a partir del respeto, del cuidado y de la valoración, como condiciones necesarias para la convivencia comunitaria y la experiencia de enseñanza-aprendizaje.

Con respecto de las interacciones con elementos capitalistas, la investigadora observa que la construcción de la identidad Tapeba se realiza de manera relacional con los no indígenas y este vínculo es perjudicial para el fortalecimiento de esta identidad. Por tanto, la Escuela Diferenciada sería el ambiente de reafirmación de la identidad Tapeba y, al mismo tiempo, intercultural por saber dialogar con las diferencias culturales.

La segunda, que trata de la educación ambiental, tiene como principal objeto de estudio a los niños Tremembé de Almofala. Este trabajo se preocupa por incluir la temática ambiental en la concepción teórica de la colonialidad, con particular interés por la Educación Ambiental Dialógica (EAD) en la Perspectiva Eco-Relacional (PER). A partir de esto, la investigadora observa que el proceso educativo de los niños indígenas Tremembé se realiza con el elemento de afectividad que da importancia a la sabiduría ancestral, dialogando con lo público y lo privado, con la escuela y el hogar. Así, se pretendió discutir la manera en que los niños son actores importantes para las estrategias decoloniales ambientales en la Educación Escolar Diferenciada Indígena (EEDI). Para eso, se observó la vinculación afectiva entre los educadores y los niños, se analizó la colonialidad/decolonialidad ambiental en la relación persona-ambiente, se entendió el significado de la niñez para los Tremembé y se estudiaron las prácticas educativas decoloniales a partir de la afectividad. Las peculiaridades de esa etnia en relación con las dimensiones políticas y espirituales son la for- 
ma de afirmación de este pueblo y los elementos de su educación diferenciada. De este modo, la memoria colectiva y la lucha por la demarcación de su territorio pueden mantenerse justamente por la afirmación de la identidad en su educación.

La autora observa que la EEDIT puede ser tanto colonializante como decolonializante. Es colonializante, cuando la educación convencional se sobrepone a las tradiciones ancestrales indígenas. Sin embargo, los Tremembé se caracterizan por no encuadrarse en esta situación, a causa de su dinámica comunitaria y a los saberes ancestrales derivados de la naturaleza. Pero hay situaciones en que se observan ejercicios colonializantes en la educación de la Escuela Maria Venância derivados de la subyugación del conocimiento indígena por el conocimiento eurocéntrico dominante, en que la función del educador debería ser la de incentivar rupturas de esas situaciones, como las lógicas punitivas y los usos de tecnologías actuales que no respeten los saberes indígenas.

\section{Consideraciones FinALES}

A partir de las investigaciones encontradas y expuestas en este artículo, se pueden observar puntos convergentes en relación con los ejes que más se repiten en la agenda de investigación en la temática discutida, así como potencialidades de nuevos ejes para estudiarse. Además, se pueden notar tendencias interdisciplinarias con respecto de la utilización de otras aportaciones teóricas junto con la de modernidad/colonialidad/decolonialidad.

Gran parte de los trabajos analizados hacen un movimiento de aproximación de la decolonialidad con la Ecología Política y la Geografía Política. Respecto al eje de género encontrado en uno de los artículos, se hace un paralelo entre la naturaleza y las cuestiones del género femenino con respecto de sus subyugaciones.

Como se puede observar, el mayor número de investigaciones trata el eje del Buen Vivir desde las perspectivas más 
pesimistas hasta aquellas que lo consideran como una alternativa decolonial. Otro punto importante por resaltarse consiste en las discusiones decoloniales latinoamericanas que tienen como uno de sus principales argumentos la crítica al EstadoNación, en que se verifica un excesivo uso de la bibliografía especializada propia de la Ciencia Política, asociada a los motivos de las movilizaciones indígenas respecto a su posición contraria al aparato estatal.

De una manera general, es posible constatar la demanda por la utilización de la perspectiva decolonial para el análisis de cuestiones indígenas y ambientales en América Latina. Analizando estas investigaciones, algunas de ellas también mostraron potencialidades de nuevos ejes para aprovecharse, como es el caso de la memoria y el uso de las teorías de la memoria. Esto revela que hay una necesidad creciente por investigar el análisis de identidad de los movimientos indígenas mediante las aportaciones de la decolonialidad y de la Ecología Política.

\section{Bibliografía}

Ballestrin, Luciana, "América Latina e o giro decolonial”, Revista Brasileira de Ciência Política, núm. 11, 2013, pp. 89-117, en http:/ / www.scielo.br/scielo.php?script=sci_arttext\&pid=S0 103-33522 013000200004

Bretón Solo de Zaldívar, Víctor, "Etnicidad, desarrollo y Buen Vivir: reflexiones críticas en perspectiva histórica”, Revista Europea de Estudios Latinoamericanos y del Caribe, núm. 95, 2013, pp. 71-95.

Castro-Gómez, Santiago, "Geografías poscoloniales y translocalizaciones narrativas de «lo latinoamericano». La crítica al colonialismo en tiempos de globalización”, en R. Follari y R. Lanz (comps.), Enfoques sobre posmodernidad en América Latina, Caracas, Sentido, 1998, pp. 157-182.

Chaparro Toro, Ana María, Visión de futuro indígena y su incidencia en el desarrollo en Colombia. El caso de las comunidades inga y ka- 
mëntza (Putamayo) ante la Iniciativa para la Integración de la Infraestructura Regional Suramericana (Irrsa), Bogotá, Universidad de los Andes, Centro Interdisciplinario de Estudios sobre Desarrollo (Cider), Ediciones Uniandes, 2015.

Cuadra Montoya, Ximena, "Conflictos ambientales en territorios indígenas y el rol de la reivindicación por el consentimiento libre, previo e informado: un análisis del caso Neltume en Chile", Justiça do Direito, vol. 29, núm. 2, 2015, pp. 294-312.

Da Costa, Wanderley Messias, "Tendências e perspectivas atuais", en Geografia Política e Geopolítica, São Paulo, Universidade de São Paulo, 2010.

Gómez Sierra, Lizeth del Carmen y Miguel Ángel León, "De los derechos ambientales a los derechos de la naturaleza: racionalidades emancipadoras del derecho ambiental y nuevas narrativas constitucionales en Colombia, Ecuador y Bolivia", Misión Jurídica, Bogotá, núm. 10, 2016, pp. 233-260.

Grosfoguel, Ramón, "Para descolonizar os estudos de economia politica e os estudos pos-coloniais: transmodernidade, pensamento de fronteira e colonialidade global", Revista Crítica de Ciências Sociais, núm. 80, 2008, pp. 115-147.

Gudynas, Eduardo y Alberto Acosta, "La renovación de la crítica al desarrollo y el Buen Vivir como alternativa", Revista Internacional de Filosofía Iberoamericana, núm. 53, 2011, pp. 71-83.

Lima, Deyseane Maria Araújo, Educação ambiental dialógica e descolonialidade com crianças indígenas Tremembé: vinculação afetiva pessoaambiente na Escola Maria Venância, tesis, Fortaleza, Universidade Federal do Ceará, 2014.

Haesbaert, Rogério y Carlos Walter Porto-Gonçalves, A nova desordem mundial, São Paulo, UNESP, 2006.

Maldonado, Efendy Emiliano, "Ecossocialismo indoamericano", Em Debate, núm. 9, 2013, pp. 56-73.

Martínez de Bringas, Asier, "La deconstrucción del concepto de propiedad: una aproximación intercultural a los derechos indígenas", Utopia y Praxis Latinoamericana, vol. 14, núm. 45, 2009, pp. 11-29. 
Mignolo, Walter, "Desobediência epistêmica: a opção descolonial e o significado de identidade em política", Cadernos de Letras da UFF, núm. 34, 2008, pp. 287-324.

Montenegro, Jorge, "Povos e comunidades tradicionais, desenvolvimento e decolonialidade: articulando um discurso fragmentado", Okara: Geografia em debate, vol. 6, núm. 1, 2012, pp. 163-174.

Quijano, Aníbal, "Colonialidade, poder, globalização e democracia”, Novos Rumos, núm. 37, 2002, pp. 4-28.

Rincón Rubio, Ana Gabriela, Ivonne Vizcarra Bordi y Humberto Thomé Ortiz, "Prácticas espirituales, ecofeminismo y maíz nativo: el caso de las mujeres matlatzincas”, Mesa temática: Feminismos transnacionales, hermenéutica y políticas de identidad, pp. 1-15, en http:/ / www.idaes.edu.ar/pdf_papeles/9-10\%2520Ponencia _Rincon.pdf

Rivera Sotelo, Aída Sofía y Luis Álvaro Pardo Becerra, “¿Qué minería aurífera, por quiénes y con fines de qué desarrollo? Una mirada a la minería aurífera en la Zona Minera Indígena Remanso Chorrobocón", Opera, núm. 14, 2014, pp. 95-117.

Santos, Marina Ghirotto, A plurinacionalidade em disputa: sumak kawsay, autonomia indigena e Estado plurinacional no Equador, tesis, São Paulo, PUC-SP, 2015.

Soriano Sánchez, Martha Angélica, "Glocalidades re-creativas. Ecología-política de la diferencia desde los caracoles zapatistas", Iberoamérica Social, núm. 2, 2014, pp. 104-115.

Stetson, George, Hydrocarbon conflict in the Peruvian Amazon: indigenous people's decolonization of development and sustainability, tesis, Fort Collins, Colorado State University, 2010.

Vargas Mariño, Andrés Felipe, Usme: A space for hope. A case study of decolonial resistance and processes of deterritorialisation and reterritorialisation in Bogotá, Colombia, tesis, Melbourne, RMIT University, 2015.

Ximenes, Ana Karolina Pessoa Bastos, Saberes ancestrais indígenas dos Tapeba de Caucaia - CE: contribuições e diálogos com a educação ambiental dialógica, tesis, Fortaleza, Universidade Federal do Ceará, 2012. 
